\title{
Adsorption of acid dyes from aqueous solution on activated bleaching earth
}

\author{
W.T. Tsai, ${ }^{\text {a,* C.Y. Chang, }{ }^{b} \text { C.H. Ing, }{ }^{\mathrm{b}} \text { and C.F. Chang }}{ }^{\mathrm{b}}$ \\ a Department of Environmental Engineering and Science, Chia Nan University of Pharmacy and Science, Tainan 717, Taiwan \\ ${ }^{\mathrm{b}}$ Graduate Institute of Environmental Engineering, National Taiwan University, Taipei 106, Taiwan
}

Received 11 November 2003; accepted 29 January 2004

Available online 24 March 2004

\begin{abstract}
In the present study, activated bleaching earth was used as clay adsorbent for an investigation of the adsorbability and adsorption kinetics of acid dyes (i.e., acid orange 51, acid blue 9 , and acid orange 10) with three different molecular sizes from aqueous solution at $25^{\circ} \mathrm{C}$ in a batch adsorber. The rate of adsorption has been investigated under the most important process parameters (i.e., initial dye concentration). A simple pseudo-second-order model has been tested to predict the adsorption rate constant, equilibrium adsorbate concentration, and equilibrium adsorption capacity by the fittings of the experimental data. The results showed that the adsorbability of the acid acids by activated bleaching earth follows the order: acid orange $51>$ acid blue $9>$ acid orange 10, parallel to the molecular weights and molecular sizes of the acid dyes. The adsorption removals (below 3\%) of acid blue 9 and acid orange 10 onto the clay adsorbent are far lower than that ( 24\%) of acid orange 51. Further, the adsorption kinetic of acid orange 51 can be well described by the pseudo-second-order reaction model. Based on the isotherm data obtained from the fittings of the adsorption kinetics, the Langmuir model appears to fit the adsorption better than the Freundlich model. The external coefficients of mass transfer of the acid orange 51 molecule across the boundary layer of adsorbent particle have also been estimated at the order of $10^{-4}-10^{-5} \mathrm{~cm} \mathrm{~s}^{-1}$ based on the film-pore model and pseudo-second-order reaction model.
\end{abstract}

(c) 2004 Elsevier Inc. All rights reserved.

Keywords: Liquid-phase adsorption; Acid dye; Activated bleaching earth; Isotherm; Kinetic modeling; Mass transfer coefficient

\section{Introduction}

Due to ever-growing demands in textiles, synthetic organic dyes are widely used for dyeing textile fibers such as cotton and polyester. However, these materials pose certain health hazards and environmental pollution. Dye effluents not only are aesthetic pollutants as far as their colors are concerned but may also interfere with light penetration in the receiving water bodies, thereby disturbing the biological processes. Further, dye effluents may contain chemicals that exhibit toxic effects toward microbial populations and can be toxic and/or carcinogenic to mammalian animal [1]. Therefore, environmental legislation has imposed stringent limits on the concentrations of pollutants that may be discharged in aqueous effluents from dyestuff manufacturing and textile industries.

\footnotetext{
* Corresponding author.

E-mail address: wwtsai@mail.chna.edu.tw (W.T. Tsai).
}

Methods of effluent treatment for dyes and/or their effluents may be divided into three main categories: physical, chemical, and biological [2,3]. Among them, adsorption technology is generally considered to be an effective method for quickly lowering the concentration of dissolved dyes in an effluent [4]. In this regard, activated carbon has been evaluated extensively for the removal of color resulting from the different classes of dyes, that is, acid, direct, basic (cationic), reactive, and disperse [5]. Despite the prolific use of this adsorbent throughout the water/wastewater treatment and other industrial applications, carbon adsorption remains an expensive process due to the high cost for the use of activated carbon [6]. This has attracted considerable research into low-cost alternative adsorbents for adsorbing or removing coloring matter and undesirable residues from plant oils in the bleaching process [7]. Activated bleaching earth, now the most widely used adsorbent in the edible industry, is generally original from acid-activated clays that act as a modified ion-exchange medium based on the chemical state of the pore surface. 
The study of the kinetics and equilibrium (isotherm) of organic pollutant adsorption onto a cost-effective adsorbent is significant in the industrial wastewater treatment system because it provides valuable insights into the mechanisms and optimal operation parameters of adsorption processes. Also, the properties of organic pollutants with respect to transport across the boundary layers of adsorbent particles are important for providing design information. In our previous papers [8-10], a series of studies of adsorption of the herbicide paraquat on activated bleaching earth were determined through the adsorption isotherms and adsorption kinetics. A fast decrease in residual paraquat concentration at a short time scale was found, implying strong electrostatic or ion-exchange interaction between the negatively charged surface and cationic paraquat.

Acid dyes are water-soluble anionic dyes and are applied to nylon, wool, silk, and modified acrylics [1]. Due to the theoretically weak interactions between the negatively charged surface in activated clays (or activated bleaching earths) and anionic dyes, there appears to be relatively little information in the literature concerning the adsorption of acid dye onto activated clay [11-15]. Chiang and Hsu [11] investigated the adsorption behavior of acid blue 9 on the activated clay. It was found that the adsorption capacity of the acidic dye was significantly smaller than that of the basic dye. Juang et al. [12] used acid-activated clay as a low-cost adsorbent for the adsorption of dyes, also showing that the adsorption capacity was comparatively high for basic dye and was lower for other kinds of dyes (e.g., acidic dye). The results of Ramakrishna and Viraraghavan [13] indicated the high removal of acidic dyes by fly ash and slag, while peat and bentonite exhibited high basic dye removals. Ho et al. [14] studied the kinetics of basic red 18 and acid blue 9 adsorption onto activated clay based on the pseudo-second order rate model. In the study of Ho and Chiang [15], they used a mixture of activated clay and activated carbon as adsorbent for the adsorption of acid blue 9 and also confirmed the pseudo-second-order rate model with good correlation. From the survey of the literature, little information on the relationships between the adsorbability of activated clay and molecular properties of acid dyes and the mass transfer coefficient of the adsorption system is found. Thus, the main objects of this paper are to (i) study the feasibility of using activated bleaching earth adsorption approach for the removals of acid dyes, (ii) evaluate the usefulness of simple pseudo-second-order models for adsorption rates or kinetics of acid dyes with high molecular weight in water solution at $25^{\circ} \mathrm{C}$, (iii) determine the applicability of common isotherm models (i.e., Langmuir and Freundlich) based on the adsorption capacities from the fittings of the adsorption rate model, and (iv) estimate the external mass transfer coefficient based on the film-pore model and pseudo-second-order adsorption rate model.

\section{Materials and methods}

\subsection{Materials}

The acid dyes used in the adsorption experiments are acid orange 51, acid blue 9, and acid orange 10, which were purchased from Aldrich Chemical Co. (St. Louis, U.S.A.). The identification information and molecular structures of these dyes are depicted in Table 1 and Fig. 1, respectively [16]. Activated bleaching earth was obtained from an edible oil workshop (Taiwan Sugar Co., Kaohsiung, Taiwan). Its properties, from the manufacturer's product brochure, are listed in Table 2. The zeta potential of the clay adsorbent was determined by a Zeta Meter System 3.0, showing that the surface of activated bleaching earth at the experimental conditions exhibits negative charges $\left(\mathrm{pH}_{\mathrm{pzc}} \approx 1.2\right)$ [10]. This implies that the clay adsorbent may be not liable to adsorb molecules of acid dye based on the electrostatic repulsion. Basically, the clay adsorbent possesses a characteristic of mesoporous structure with BET surface area of $245 \mathrm{~m}^{2} \mathrm{~g}^{-1}$, which is very close to our previous measurements, ranging from 229 to $267 \mathrm{~m}^{2} / \mathrm{g}$ [9].

\subsection{Adsorption kinetics}

All the experiments with adsorption kinetics were carried out in a ca. 5-L stirred batch adsorber with four baffles as described previously [17]. The jacketed adsorber was maintained at isothermal condition (i.e., $25^{\circ} \mathrm{C}$ ) with an outer circulating-water bath prior to all of the experiments. For each experiment, $3.7 \mathrm{~L}$ of the acid dye solution at specified initial concentration was continuously stirred with a certain amount of the adsorbent dried in an oven $\left(105^{\circ} \mathrm{C}\right)$

Table 1

Some properties of the acid dyes used in the present study ${ }^{a}$

\begin{tabular}{|c|c|c|c|}
\hline Property & Acid orange 51 & Acid blue 9 & Acid orange 10 \\
\hline CAS & $8003-88-1$ & $3844-45-9$ & $1936-15-8$ \\
\hline C.I. & 26550 & 42090 & 16230 \\
\hline Chemical formula & $\mathrm{C}_{36} \mathrm{H}_{26} \mathrm{O}_{11} \mathrm{~N}_{6} \mathrm{~S}_{3} \mathrm{Na}_{2}$ & $\mathrm{C}_{37} \mathrm{H}_{34} \mathrm{O}_{9} \mathrm{~N}_{2} \mathrm{~S}_{3} \mathrm{Na}_{2}$ & $\mathrm{C}_{16} \mathrm{H}_{10} \mathrm{O}_{7} \mathrm{~N}_{2} \mathrm{~S}_{2} \mathrm{Na}_{2}$ \\
\hline Molecular weight & 860.81 & 792.86 & 452.38 \\
\hline Molecular size ${ }^{\mathrm{b}}$ & $2.96 \times 0.92 \times 0.90 \mathrm{~nm}$ & $1.88 \times 1.47 \times 1.07 \mathrm{~nm}$ & $1.38 \times 0.83 \times 0.41 \mathrm{~nm}$ \\
\hline Dye content & $\sim 50 \%$ & $\sim 65 \%$ & $\sim 80 \%$ \\
\hline$\lambda_{\max }(\mathrm{nm})$ & 446 & 625 & 475 \\
\hline
\end{tabular}

a Purchased from Aldrich Co. (U.S.A.).

b See Ref. [16]. 
for more than $24 \mathrm{~h}$. Thus, the adsorption conditions were further set at an agitation speed of $800 \mathrm{rpm}$ in the present work. In the adsorbing stage, the solution (ca. $20 \mathrm{~cm}^{3}$ ) was sampled from the adsorber at specified intervals up to $45 \mathrm{~h}$. It was then treated with centrifugation for solid-liquid separation. The acid dye concentration analysis of decant solution was immediately made by using spectrophotometer

(a) Acid orange 51

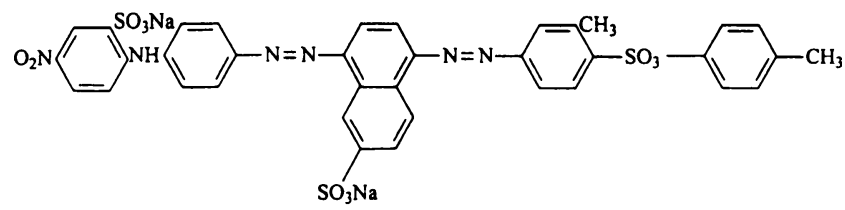

(b) Acid blue 9<smiles>CCN(Cc1cccc(S(C)(=O)=O)c1)c1ccc(C(=C2C=CC(=[N+](CC)Cc3ccccc3)C=C2)c2ccccc2)cc1</smiles>

(c) Acid orange 10

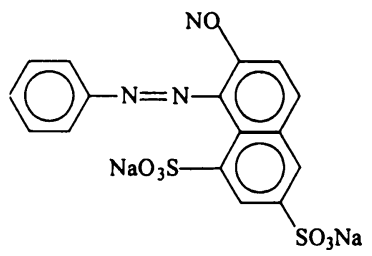

Fig. 1. Molecular structures of acid dyes used in this study: (a) acid orange 51, (b) acid blue 9, and (c) acid orange 10 .

Table 2

Properties of activated bleaching earth used in this study a

\begin{tabular}{|c|c|}
\hline Properties & Values \\
\hline \multicolumn{2}{|l|}{ Chemical composition (\%) } \\
\hline Loss on ignition ${ }^{\mathrm{b}}$ & $4.24-10.27$ \\
\hline $\mathrm{SiO}_{2}$ & 73.49-78.16 \\
\hline $\mathrm{Al}_{2} \mathrm{O}_{3}$ & $6.94-10.63$ \\
\hline $\mathrm{Fe}_{2} \mathrm{O}_{3}$ & $1.53-4.45$ \\
\hline $\mathrm{MgO}$ & $1.19-2.84$ \\
\hline $\mathrm{CaO}$ & $0.19-0.92$ \\
\hline $\mathrm{pH}(10 \%$ suspension $)$ & $2.5-3.5$ \\
\hline Moisture $\left(\%\right.$, loss on drying at $\left.100^{\circ} \mathrm{C}\right)$ & $7.0-9.0$ \\
\hline Residual acidity ( $\mathrm{KOH} \mathrm{mg} \mathrm{g}^{-1}$ ) & $0.5-1.5$ \\
\hline \multicolumn{2}{|l|}{ Physical properties } \\
\hline True specific gravity & $2.3-2.5$ \\
\hline Bulk density $\left(\mathrm{g} \mathrm{cm}^{-3}\right)$ & $0.65-0.75$ \\
\hline BET surface area $\left(\mathrm{m}^{2} \mathrm{~g}^{-1}\right)$ & 245 \\
\hline Fineness ( $\%$, pass through $88 \mu \mathrm{m}$ sieve) & $88-92$ \\
\hline \multicolumn{2}{|l|}{ Particle size distribution (\%) } \\
\hline $0-10 \mu \mathrm{m}$ & 7.3 \\
\hline $10-20 \mu \mathrm{m}$ & 17.1 \\
\hline $20-30 \mu \mathrm{m}$ & 20.4 \\
\hline $30-40 \mu \mathrm{m}$ & 26.6 \\
\hline
\end{tabular}

a Supplied by the manufacturer (Mizusawa Co., Japan).

b Loss on drying at $110^{\circ} \mathrm{C}$.
(Model GENESYS 20; Thermo Spectronic Co., U.S.A.). The amount of acid dye adsorbed $\left(q_{t}, \mathrm{mg} \mathrm{g}^{-1}\right)$ was determined as

$q_{t}=\left(C_{0}-C_{t}\right) V / m$,

where $C_{0}$ and $C_{t}$ are the initial and liquid-phase concentrations of acid dye solution at time $t\left(\mathrm{mg} \mathrm{dm}^{-3}\right)$, respectively, $V$ is the volume (ca. $3.7 \mathrm{dm}^{3}$ ) of aqueous solution containing acid dye, and $m$ is the mass of dry clay adsorbent used (g). All of the experimental data were carried out in duplicate for precisely calculating the adsorption kinetics with a simple pseudo-second-order method.

\section{Results and discussion}

\subsection{Adsorbability of acid dyes}

Figs. 2-4 show the rate of adsorption on activated bleaching earth for acid orange 51, acid blue 9, and acid orange 10 , respectively. It can be seen that preliminary investigations of the adsorption removal by the clay adsorbent have indicated that the process occurs for acid orange 51, not in the cases for acid blue 9 and acid orange 10. The decrease in residual

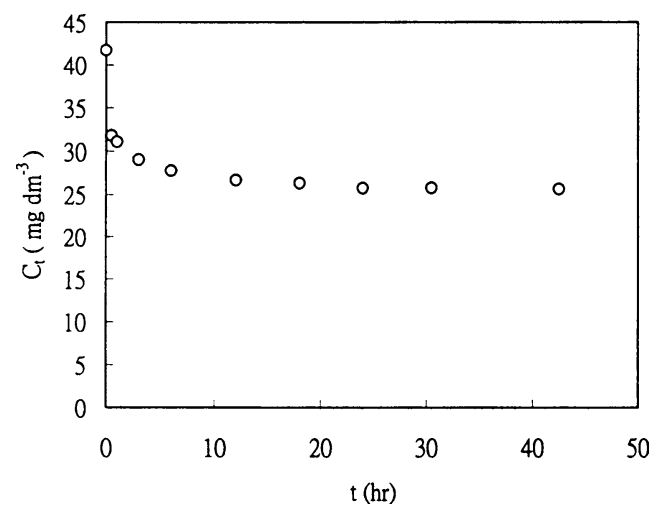

Fig. 2. Plot of concentration versus time for acid orange 51 (initial concentration $=41.7 \mathrm{mg} \mathrm{dm}^{-3}$, adsorbent dosage $=12 \mathrm{~g}$ in $3.7 \mathrm{dm}^{-3}$, agitation speed $=800 \mathrm{rpm}$, and temperature $=25^{\circ} \mathrm{C}$ ).

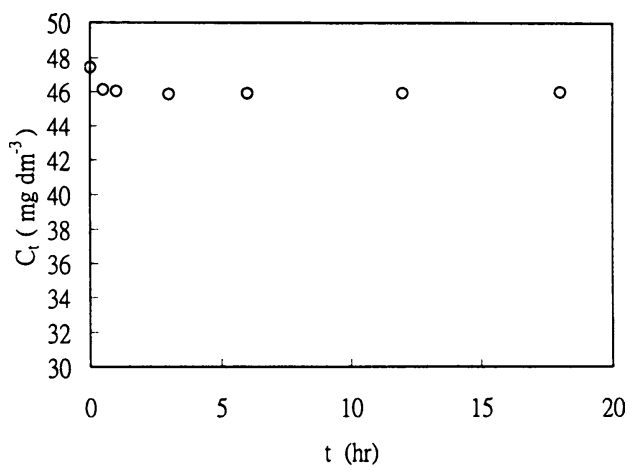

Fig. 3. Plot of concentration versus time for acid blue 9 (initial concentration $=47.4 \mathrm{mg} \mathrm{dm}^{-3}$, adsorbent dosage $=6 \mathrm{~g}$ in $3.7 \mathrm{dm}^{-3}$, agitation speed $=800 \mathrm{rpm}$, and temperature $=25^{\circ} \mathrm{C}$ ). 


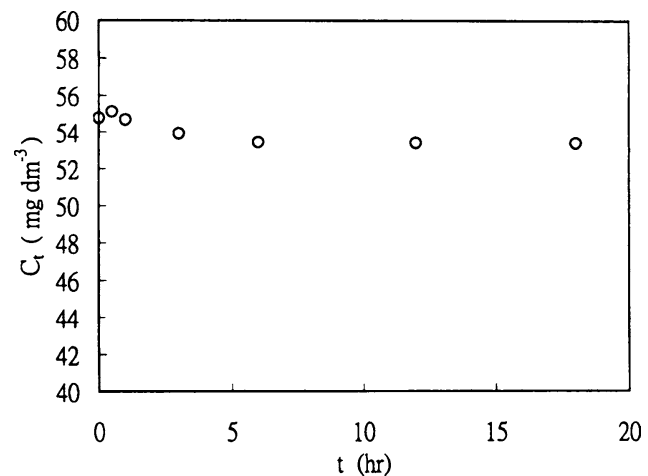

Fig. 4. Plot of concentration versus time for acid orange 10 (initial concen-

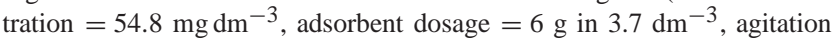
speed $=800 \mathrm{rpm}$, and temperature $=25^{\circ} \mathrm{C}$ ).

acid orange 51 concentration means the increase in amount of acid orange 51 adsorbed as a function of time until the adsorption of acid orange 51 approached to remain constant, implying that adsorption equilibrium has been reached. After the lapse of ca. $10 \mathrm{~h}$, a gradual approach to the limiting adsorption was observed. Evidently, the adsorption removals (below 3\%) of acid blue 9 and acid orange 10 on the clay adsorbent are far lower than that $(\sim 24 \%)$ of acid orange 51 . The adsorbability of the acid dyes by activated bleaching earth thus follows the sequence: acid orange $51>$ acid blue 9 $>$ acid orange 10 . It is interested that this adsorbability order is parallel to the molecular weights and molecular sizes of the acid dyes listed in Table 1, showing that the adsorption of acid dyes by activating bleaching earth is still dependent on dye property. These results may be related to show that the activated bleaching earth is not an effective adsorbent for the anionic dyes due to the negatively charged surface of the clay adsorbent, which is consistent with other studies $[12,13]$. Although such dyes are not readily adsorbed onto the clay adsorbent surface due to their sulfonic and azo groups [4], the van der Waals forces derived from the adsorption potential still pose a significant role in encountering the electrostatic repulsion between the anionic dye and the clay adsorbent.

\subsection{Adsorption kinetics}

In the present work, a simple kinetic analysis of adsorption, a pseudo-second-order equation, is used to fit experimental data in the form $[14,15,18,19]$

$d q_{t} / d t=k\left(q_{e}-q_{t}\right)^{2}$,

where $k$ is the pseudo-second-order rate constant $\left(\mathrm{g} \mathrm{mg}^{-1}\right.$ $\left.\mathrm{h}^{-1}\right), q_{e}$ is the amount of acid dye adsorbed at equilibrium $\left(\mathrm{mg} \mathrm{g}^{-1}\right)$, and $q_{t}$ is the amount of acid dye adsorbed at time $t$ $\left(\mathrm{mg} \mathrm{g}^{-1}\right)$. Integrating Eq. (2) for the boundary conditions $t=0$ to $t=t$ and $q_{t}=0$ to $q_{t}=q_{t}$, gives

$1 /\left(q_{e}-q_{t}\right)=1 / q_{e}+k t$.

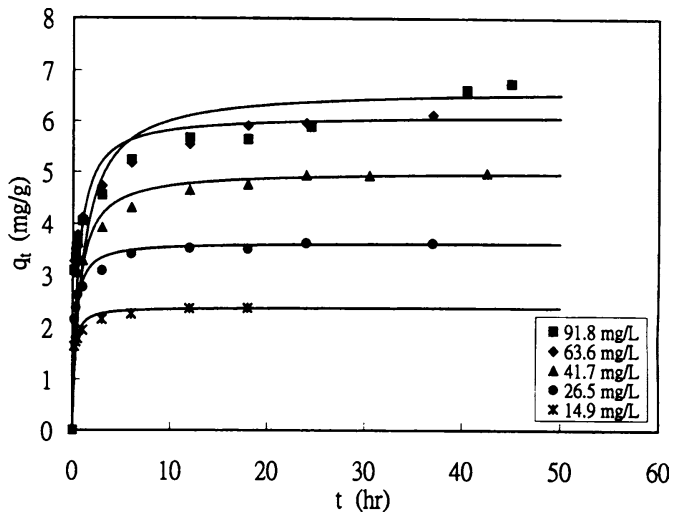

Fig. 5. Plots of adsorbed acid orange 51 amount versus time at various initial concentrations. Adsorption conditions: adsorbent dosage $=12 \mathrm{~g}$ in $3.7 \mathrm{dm}^{-3}$, agitation speed $=800 \mathrm{rpm}$, and temperature $=25^{\circ} \mathrm{C}$. Symbols: experimental data; full lines: calculated from pseudo-second-order adsorption kinetics or Eq. (4).

Equation (3) can be rearranged to obtain a linear form:

$t / q_{t}=1 /\left(k q_{e}^{2}\right)+\left(1 / q_{e}\right) t$.

The rate parameters, $k$ and $q_{e}$, can be directly obtained from the intercept and slope of the plot of $\left(t / q_{t}\right)$ against $t$. The equilibrium concentration (i.e., $C_{e}$ ) can be further calculated from Eq. (1), as the value of $q_{e}$ has been obtained from the fitting of Eq. (4).

The effects of the initial acid dye 51 concentrations on the rate and extent of adsorption of activated bleaching earth were studied at an adsorbent dosage of $12 \mathrm{~g}$ in $3.7 \mathrm{dm}^{-3}$, a mixing speed of $800 \mathrm{rpm}$, and a temperature of $25^{\circ} \mathrm{C}$, as shown in Fig. 5, where the experimental data are shown as discrete points and those obtained from the model by solid lines. It is evident from Fig. 5 that the rate of adsorption decreased with time until it gradually approached a plateau due to the continuous decrease in the concentration driving force. The kinetic data obtained from batch studies have been analyzed by using the pseudo-second-order model. Values of $k$, $q_{e}$, correlation coefficient $\left(R^{2}\right)$, and $C_{e}$ for the acid dye 51, computed from Eq. (4) and Eq. (1), are listed in Table 3, from which it will be seen that the kinetics of the dye adsorption on the clay adsorbent follows this model with the correlation coefficients of higher than 0.999 for all the system in this study, excluding the initial concentration $91.8 \mathrm{mg} \mathrm{dm}^{-3}$ where the correlation coefficient slightly falls on 0.994 . From the results in Table 3, the adsorption capacity (i.e., $q_{e}$ ) increased as the initial dye concentration (i.e., $\left.C_{0}\right)$ and equilibrium concentration (i.e., $C_{e}$ ) increased, which is also consistent with similar studies $[11,14,15]$. However, it was found that the rate constant (i.e., $k$ ) and adsorption capacity (i.e., $\left.q_{e}\right)$ are significantly lower than those of the adsorption for the cationic paraquat-clay adsorbent system [8-10].

\subsection{Adsorption isotherm}

It is necessary to establish the most appropriate correlations for the equilibrium data in the design of adsorption sys- 
tems. Two common isotherm equations have been tested in the present study: Langmuir and Freundlich models [20,21]. Applicability of the isotherm equations was compared by judging the correlation coefficients, $R^{2}$ :

Langmuir: $\quad C_{e} / q_{e}=1 /\left(K_{L} q_{m}\right)+\left(1 / q_{m}\right) C_{e}$,

Freundlich: $q_{e}=K_{F} C_{e}^{1 / n}$.

In Eq. (5), $C_{e}$ and $q_{e}$ are as defined in Eq. (2), $K_{L}$ is a direct measure for the intensity of the adsorption process or related to the heat of adsorption $\left(\mathrm{dm}^{3} \mathrm{mg}^{-1}\right)$, and $q_{m}$ is a constant related to the area occupied by a monolayer of absorbate, reflecting the limiting adsorption capacity $\left(\mathrm{mg} \mathrm{g}^{-1}\right)$. From a plot of $C_{e} / q_{e}$ vs $C_{e}, q_{m}$ and $K_{L}$ can be determined from the slope and intercept. In Eq. (6), $K_{F}$ is a constant for the system, related to the bonding energy. $K_{F}$ can be defined as adsorption or distribution coefficient and represents the quantity of dye adsorbed onto adsorbents for a unit equilibrium concentration (i.e., $C_{e}=1 \mathrm{mg} \mathrm{dm}^{-3}$ ). The slope $1 / n$, ranging between 0 and 1 , is a measure for the adsorption intensity or surface heterogeneity [22]. A value for $1 / n$ below one indicates a normal Langmuir isotherm while $1 / n$ above one is indicative for a cooperative adsorption [23]. A plot of $\ln q_{e}$ vs $C_{e}$ enables the empirical constants $K_{F}$ and $1 / n$ to be determined from the intercept and slope of the linear regression.

Table 4 presents the results of Langmuir and Freundlich isotherm fits of acid orange 51 using the adsorption capacity data from Table 3 at $25^{\circ} \mathrm{C}$. Obviously, it can be seen in Fig. 6 that the Langmuir model yields a somewhat better fit than the Freundlich model, as reflected by correlation coefficients $\left(R^{2}\right)$ of 0.998 and 0.966 , respectively. It is noted in Table 4 that the monolayer adsorption capacity (i.e., $q_{m}=$ $8.45 \mathrm{mg} \mathrm{g}^{-1}$ ) is significantly lower than that of paraquat adsorption on the activated clay [8-10]. As also illustrated in Table 4 , the value of $1 / n$ is 0.460 , which indicates somewhat favorable adsorption [23], but the adsorption favorability is

Table 3

Kinetic parameters for adsorption of acid orange 51 onto activated bleaching earth at various initial concentrations ${ }^{\mathrm{a}}$

\begin{tabular}{ccccc}
\hline $\begin{array}{c}C_{0} \\
\left(\mathrm{mg} \mathrm{dm}^{-3}\right)\end{array}$ & $\begin{array}{c}k \\
\left(\mathrm{~g} \mathrm{mg}^{-1} \mathrm{~h}^{-1}\right)\end{array}$ & $\begin{array}{c}q_{e} \\
\left(\mathrm{mg} \mathrm{g}^{-1}\right)\end{array}$ & $\begin{array}{c}\text { Correlation } \\
\text { coefficient }\end{array}$ & $\begin{array}{c}C_{e} \\
\left(\mathrm{mg} \mathrm{dm}^{-3}\right)\end{array}$ \\
\hline 14.9 & 2.56 & 2.39 & 0.9997 & 7.1 \\
26.5 & 1.03 & 3.64 & 0.9997 & 14.7 \\
41.7 & 0.33 & 5.02 & 0.9995 & 25.4 \\
63.6 & 0.31 & 6.12 & 0.9988 & 43.7 \\
91.8 & 0.14 & 6.65 & 0.9941 & 70.3 \\
\hline
\end{tabular}

a Adsorption conditions: adsorbent dosage $=12 \mathrm{~g}$ in $3.7 \mathrm{dm}^{-3}$, agitation speed $=800 \mathrm{rpm}$, and temperature $=25^{\circ} \mathrm{C}$. evidently less than for the adsorption systems of paraquatclay [8-10] and dye-carbon [24,25], respectively.

\subsection{Mass transfer coefficient}

According to the typical adsorption model [20,21], there are two main mass transfer resistances, external diffusion across the boundary layer surrounding each adsorbent particle and internal diffusion into the porous particle. Based on the film-pore diffusion model for describing the process [21], external mass transfer can be equated to

$N_{t}=k_{f} A\left(C_{t}-C_{s}\right)$,

where $N_{t}$ is the diffusion rate across the film layer surrounding the adsorbent particle. $k_{f}$ is the external mass transfer coefficient. Its reciprocal is a measure of the resistance in the film layer. $A$ is the external surface area of adsorbent particles. $C_{s}$ is the adsorbate equilibrium concentration at the surface of adsorbent particle. $C_{t}$ is as defined in Eq. (1). From the mass balance, diffusion rate can be also described by combining Eq. (1) as follows:

$N_{t}=-V d C_{t} / d t=m d q_{t} / d t$.

Using the initial conditions (i.e., $C_{t}=C_{0}$ and $C_{s}=0$ at $t=$ $0)$, therefore,

$\left(N_{t}\right)_{t \rightarrow 0}=k_{f} A C_{0}$.

Combining Eqs. (2), (8), and (9), the external mass transfer coefficient, $k_{f}$, can be evaluated by the equation

$k_{f}=m k q_{e}^{2} /\left(C_{0} A\right)$.

In the previous study [9], the mean particle diameter for the clay adsorbent was determined to be $2.244 \times 10^{-5} \mathrm{~m}$. The

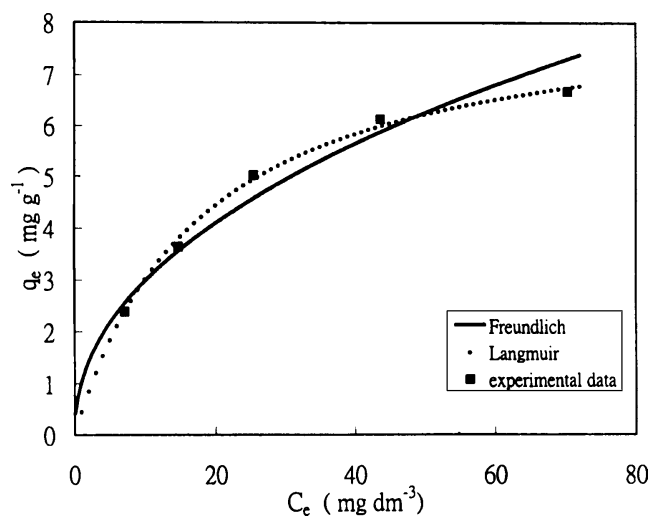

Fig. 6. Isotherms of acid orange 51 adsorption on activated bleaching earth at $25^{\circ} \mathrm{C}$. Symbols: data from the fittings of pseudo-second-order adsorption kinetics; full lines: calculated from Langmuir and Freundlich models.

Table 4

Isotherm parameters for adsorption of acid orange 51 onto activated bleaching earth in water solutions at $25^{\circ} \mathrm{C}$

\begin{tabular}{cccccc}
\hline & Langmuir & & \multicolumn{3}{c}{ Freundlich } \\
\cline { 2 - 5 }$q_{m}\left(\mathrm{mg} \mathrm{g}^{-1}\right)$ & $K_{L}\left(\mathrm{dm}^{3} \mathrm{mg}^{-1}\right)$ & $R^{2}$ & & $K_{F}\left(\mathrm{mg} \mathrm{g}^{-1}\left(\mathrm{dm}^{3} \mathrm{mg}^{-1}\right)^{1 / n}\right)$ & $1 / n(-)$ \\
\hline 8.45 & 0.0552 & 0.9979 & 1.03 & $R^{2}$ \\
\hline
\end{tabular}


Table 5

External mass transfer coefficient for adsorption of acid orange 51 onto activated bleaching earth at various initial concentrations

\begin{tabular}{cc}
\hline$C_{0}\left(\mathrm{mg} \mathrm{dm}^{-3}\right)$ & $k_{f}\left(\mathrm{~cm} \mathrm{~s}^{-1}\right)$ \\
\hline 14.9 & $1.29 \times 10^{-4}$ \\
26.5 & $6.76 \times 10^{-5}$ \\
41.7 & $2.61 \times 10^{-5}$ \\
63.6 & $2.42 \times 10^{-5}$ \\
91.8 & $8.97 \times 10^{-6}$ \\
\hline
\end{tabular}

value of the external surface area per spherical particle is thus estimated to be $1.58 \times 10^{-9} \mathrm{~m}^{2}$. The total number of adsorbent particles can be roughly estimated to be $1.61 \times 10^{9}$ based on the adsorbent mass (i.e., $m=12 \mathrm{~g}$ ) and particle density $\left(=1.261 \mathrm{~g} \mathrm{~cm}^{-3}\right)$ [26]. Therefore, the values of $k_{f}$ at various $C_{0}$ can be obtained based on $m=12 \mathrm{~g}, A=2.54 \mathrm{~m}^{2}$, and data in Table 3.

Table 5 gives the obtained values of $k_{f}$ ranging from $8.97 \times 10^{-6}$ to $1.29 \times 10^{-4} \mathrm{~cm} \mathrm{~s}^{-1}$. The obtained values of the external mass transfer coefficient are compared to the reported data found in literatures [11,27-30]. McKay et al. [27] conducted the adsorption of dyes (e.g., acid red 114) onto bagasse pitch during the external transport processes. The value of $k_{f}$ is $4.73 \times 10^{-6} \mathrm{~cm} \mathrm{~s}^{-1}$, which was obtained by the initial rate (slope) method. Nassar and El-Geundi [28] studied the external mass transport coefficient during the adsorption of acid dye (i.e., acid blue 25) onto bagasse pith, showing that the value of $k_{f}$ is $4.73 \times 10^{-4} \mathrm{~cm} \mathrm{~s}^{-1}$, which was also obtained by the initial rate (slope) method. Chiang and Hsu [11] investigated the adsorption behavior of acid blue 9 on the activated clay. They found the values of $k_{f}$ by the differential and integration methods, indicating that the values of $k_{f}$ decreased with increase of initial adsorbate concentration. Also, the ranges of $k_{f}$ thus obtained are approximate to be the order of $10^{-4} \mathrm{~cm} \mathrm{~s}^{-1}$, which are in agreement with those found in the present study. Hsu et al. [29] used activated clay to study the adsorption of basic dyes including the differentiation and integration methods for the calculation of external mass transfer coefficients. Their results showed that the values $\left(10^{-4}-10^{-5} \mathrm{~cm} \mathrm{~s}^{-1}\right)$ of the mass transfer coefficient were found to be lower at higher initial concentrations. Al-Qodah [30] determined the external mass transfer coefficient for the adsorption of reactive dyes on shale oil ash by using two-resistance model. Comparing the model predictions with the experimental curves by means by the best-fit approach, the result showed that the coefficient (i.e., $2.5 \times 10^{-4} \mathrm{~cm} \mathrm{~s}^{-1}$ ) was not affected by varying the initial dye concentration. Notably, a nonlinear combination of external mass transfer and effective diffusion determines the overall shape of the concentration decay curve in the solute adsorption onto porous particle. The former generally takes the first stage of the process, after which the later becomes dominant throughout the process until equilibrium. Further works would be helpful in order to elucidate pore diffusion and surface diffusion (i.e., the migration of solute molecules on the pore walls) of acid orange 51 molecule, and simulate the adsorption system based on either a liquid film resistance and/or pore diffusion resistance, because the surface diffusion may play an important role in the transport contribution [21].

\section{Conclusions}

The adsorbability and adsorption rate of acid dyes with different molecular sizes on activated bleaching earth from aqueous solution at $25^{\circ} \mathrm{C}$ has been examined. The following conclusions can be drawn:

- Basically, the activated bleaching earth is not an effective adsorbent for the anionic dyes possibly due to the negatively charged surface of the clay adsorbent. However, the van der Waals forces derived from the adsorption potential still pose a significant role in encountering the electrostatic repulsion between the clay adsorbent and the anionic dye with high molecular weight.

- The adsorbability of the acid dyes by activated bleaching earth follows the order: acid orange $51>$ acid blue 9 $>$ acid orange 10, which is parallel to the molecular weights and molecular sizes of the acid dyes.

- The adsorption kinetics of acid orange 51 can be well described by the pseudo-second-order model equation. Also, the rate constant of adsorption was found to decrease by increasing the initial concentration.

- From the isotherm data obtained from the fittings of the pseudo-second-order model, the Langmuir model yields a somewhat better fit than the Freundlich model.

- The external mass transfer coefficients (the order of $10^{-4}-10^{-5} \mathrm{~cm} \mathrm{~s}^{-1}$ ), estimated based on the pore-film model and pseudo-second-order rate model, are compared to the published data in literatures.

\section{Acknowledgment}

This research was supported by the NSC (National Science Council), Taiwan, under Contract NSC 91-2211-E-041005 .

\section{References}

[1] A. Reife, in: J.I. Kroschwitz, M. Howe-Grant (Eds.), Kirk-Othmer Encyclopedia of Chemical Technology, vol. 8, fourth ed., Wiley, New York, 1993.

[2] Y.M. Slokar, A. Majcen Le Marechal, Dyes Pigments 37 (1998) 335.

[3] O.J. Hao, H. Kim, P.C. Chiang, Crit. Rev. Environ. Sci. Technol. 30 (2000) 449.

[4] A. Reife, H.S. Freeman, in: A. Reife, H.S. Freeman (Eds.), Environmental Chemistry of Dyes and Pigments, Wiley, New York, 1996.

[5] S.J. Allen, in: G. McKay (Ed.), Use of Adsorbents for the Removal of Pollutants from Wastewaters, CRC Press, Boca Raton, FL, 1996.

[6] S.J.T. Pollard, G.D. Fowler, C.J. Sollars, R. Perry, Sci. Total Environ. 116 (1992) 31. 
[7] H.B.W. Patterson, J. Am. Oil Chem. Soc. 53 (1976) 339.

[8] W.T. Tsai, M.F. Hsieh, H.F. Sun, S.F. Chien, H.P. Chen, Bull. Environ. Contam. Toxicol. 69 (2002) 189.

[9] W.T. Tsai, C.W. Lai, K.J. Hsien, J. Colloid Interface Sci. 263 (2003) 29.

[10] W.T. Tsai, C.W. Lai, K.J. Hsien, Colloids Surf. A 224 (2003) 99.

[11] C.C. Chiang, Y.C. Hsu, J. Chin. Colloid Interface Soc. 20 (1997) 215.

[12] R.S. Juang, F.C. Wu, R.L. Tseng, Environ. Technol. 18 (1997) 525.

[13] K.R. Ramakrishna, T. Viraraghavan, Water Sci. Technol. 36 (1997) 189.

[14] Y.S. Ho, C.C. Chiang, Y.C. Hsu, Sep. Sci. Technol. 36 (2001) 2473.

[15] Y.S. Ho, C.C. Chiang, Adsorption 7 (2001) 139.

[16] H. Tamai, T. Yoshida, M. Sasaki, H. Yasuda, Carbon 37 (1997) 983.

[17] C.Y. Chang, W.T. Tsai, C.H. Ing, C.F. Chang, J. Colloid Interface Sci. 260 (2003) 273.

[18] Y.S. Ho, G. McKay, Water Res. 34 (2000) 735.
[19] F.C. Wu, R.L. Tseng, R.S. Juang, Water Res. 35 (2001) 613.

[20] K.E. Noll, V. Gounaris, W.S. Hou, Adsorption Technology for Air and Water Pollution Control, Lewis, Chelsea, MI, 1992.

[21] B. Al Duri, in: G. McKay (Ed.), Use of Adsorbents for the Removal of Pollutants from Wastewaters, CRC Press, Boca Raton, FL, 1996.

[22] F. Haghseresht, G. Lu, Energy Fuels 12 (1998) 1100.

[23] K. Fytianos, E. Voudrias, E. Kokkalis, Chemosphere 40 (2000) 3.

[24] L.B. Khalil, B.S. Girgis, Adsorpt. Sci. Technol. 16 (1998) 405.

[25] W.T. Tsai, C.Y. Chang, M.C. Lin, S.F. Chien, H.F. Sun, M.F. Hsieh, Chemosphere 45 (2001) 51.

[26] W.T. Tsai, H.P. Chen, S.F. Chien, H.F. Sun, M.F. Hsieh, J. Anal. Appl. Pyrol. 63 (2002) 157.

[27] G. McKay, M.S. El-Geundi, M.M. Nassar, Water Res. 22 (1988) 1527.

[28] M.M. Nassar, M.S. El-Geundi, Adsorpt. Sci. Technol. 11 (1994) 73.

[29] Y.C. Hsu, C.C. Chiang, M.F. Yu, Sep. Sci. Technol. 32 (1997) 2513.

[30] Z. Al-Qodah, Water Res. 34 (2000) 4295. 